\title{
The Challenge of Comparing Fluid Categories: Race and Class in Educational Research
}

\author{
Liz Jackson ${ }^{\text {a }}$ \\ University of Hong Kong
}

\begin{abstract}
Race and class are two of the most significant factors associated with educational inequality within and across societies. However, their definitions and significance vary over time, and from one place to another. As subjective factors related to identity, they also impact on one another in their effects on educational access and equity. These issues create challenges for conducting comparative educational research that effectively explores one or both of these factors. This essay examines challenges employing race and class in comparative educational research. Race and class are analysed separately, illustrating that ethical and political issues, not just conceptual miscommunications, are at stake in defining and using these categories. The geographical and political complexity of using race and class are also reflected on more generally, and the argument is put forward that analytic and self-reflexive understanding of diversity is needed for the development of fruitful understanding of the relationship between race and class and educational equity and justice.
\end{abstract}

KEYWORDS: race, class, educational research, social justice, equality, inequality

\section{Introduction}

Among various factors associated with educational inequality within and across societies, race and class are two of the most common and significant. However, their definitions and significance vary over time, and from one place to another. As subjective factors related to identity-another fluid concept - they rarely can be seen as functioning independently from one another, but instead impact on one another in their effects on educational access and equity. These issues create challenges for conducting comparative educational research that effectively explores one or both of these factors, and should be considered by researchers who are concerned with social inequality in education.

This essay examines challenges involved with employing race and class in comparative educational research. In what follows, I first analyse race and class separately, giving a historical overview of each that highlights the way that race and class must be defined within a particular social and cultural context before it can be applied as a factor in educational research. As each section also illustrates, ethical and political issues, not just conceptual miscommunications, are at stake in defining and using categories of race and class to understand the social world. Therefore educational researchers bear responsibility to be critical and analytic when using these categories, not aiming at the attainment of universalistic claims about their findings. In the last section the geographical and political complexity of using categories of race and class in comparative educational research will be reflected on more generally, and the argument will be put forward that analytic and self-reflexive understanding of diversity is needed by those working in this field if we are develop fruitful understanding of the relationship between such identity factors and the demands of educational equity and justice.

\section{Race}

The indigene is a semiotic pawn on a chess board under the control of the white signmaker. Whether the context is Canada, New Zealand, or Australia becomes a minor issue since the

a Correspondence can be directed to: lizjackson@hku.hk 
game, the signmaking is all happening on one form of board, within one field of discourse, that of British imperialism. Terms such as "war-dance," "war-whoop," "tomahawk," and "dusky" are immediately suggestive everywhere of the indigene. To a North American, at least the first three would seem to be obvious Indianisms, but they are immediately suggestive everywhere of the indigene (Goldie, 1989, p.232).

The perception of the other as alien, and (typically) inferior, seems to be nearly universal within human communities throughout history. The other has been defined within a society as an other of religion, cult, gender, caste, and so on (Sollors, 1986). When geographically separate groups encounter each other in history, their observations almost invariably focus on so called 'essential' differences between themselves and the others. In such contexts, race and ethnicity are major categories for conceiving these differences.

Historically, modern racial classifications of humankind emerged in the 1600s (Keevak, 2011). Early social scientists elaborated perceived physical and apparently intellectual differences between groups, likening race to specie, under essentialist racism: "the belief that there are essential qualitative, biological differences between different races" (Kincheloe \& Steinberg, 1997, p.170). Western Europeans tested, defined and redefined these conceptions from the seventeenth to the twentieth centuries. Though they saw their research as rigorous and objective, their studies enabled unequal treatment of individuals within and across societies, as their categorisations were hierarchical (Keevak, 2011). Social Darwinism of the late-nineteenth and early-twentieth centuries depicted race groups as evolving in parallel on one playing field, with 'whites' overtaking 'black,' 'red,' 'yellow' and 'brown' groups. Such racial lenses fuelled ghastly events across the world: eugenics in the United States, the Nazi German Holocaust, and Apartheid in South Africa, where a pencil would be placed in children's hair to judge its thickness, thereby determining their race and the schools they would attend-regardless of their achievement, neighbourhood or preference.

Whether race should be seen as a valid genetic category remains controversial. However, since the mid-twentieth century, social scientists have increasingly portrayed race as a social construction, rather than a biological trait. From a cross-cultural view, it is hard to deny that race is socially constructed, given the myriad definitions of it across societies. For instance, to be 'black' or 'colored' in early United States history meant to have 'one drop' of 'black blood'-any semblance of African descent-while in Apartheid South Africa, blackness was defined exclusively, with 'one drop' of 'white blood' - any 'white' characteristics - marking one as 'colored,' distinct there from 'black.' Early on, Europeans described Asians as "white, like ourselves," casting Asians as 'yellow' only as racial categorisations became popular in the 1600s (Keevak, 2011).

Against this backdrop some argue that race should no longer be treated as a serious category by researchers, particularly in the social sciences. As Ravitch has argued, "No serious scholar would claim that all Europeans and white Americans are part of the same culture, or that all Asians are part of the same culture...Any categorization this broad is essentially meaningless and useless" (1990, p.342). Because individual identity is fluid, impacted by many factors beyond race (such as gender, religion and even height and weight), some find race-related thought divisive and unnecessary, as racist expressions and practices have become taboo across many societies across the globe. However, others argue that race continues to matter today as a factor impacting on individual opportunity, despite increased awareness of its social construction.

Critical race theorists elaborate institutional racism as a remaining hurdle to equality and equity across societies. First, there is a kind of networking effect, as Kincheloe and Steinberg (1997, p.174) describe:

Most institutions develop informal cultural practices that are internalized by their members. Such institutional cultures are diverse in their expression and specific to particular organizations; but they do tend to be white...The organization "thinks" and carries on its 
business in a white manner. White people via their cultural experiences are perceived to be better suited for inclusion in these cultures, though class and gender issues obviously affect dimensions of "suitability" as well.

In relation, Padilla (1997) elaborates a "multiplier effect" (quoted in Jackson, 2008, p.22) impacting on groups differently at the individual level:

[A group member's] rise may benefit members of her group and may reduce outsiders' prejudice against group members. Her material success may enable her to support group related institutions. Her access to power may enable her to promote or protect the interests of other group members. She may serve as an example or inspiration for young members and thus encourage their pursuit of higher education and professional career paths.

Others speak of an "invisible knapsack" of privileges those cast as white in a society possess: benefits they receive from race, despite de jure racial equality in many societies today. McIntosh (1990) lists numerous privileges white people enjoy in daily life: from not being harassed while shopping for jewellery, to finding bandages that match one's skin colour. A wide variety of evidence from personal experience (hooks, 1994; Ladson-Billings, 1998), to qualitative discourse analysis (McCarthy, 2003), to statistical data suggest that race impacts life experiences and opportunities from birth, despite its socially constructed, fluid status. Relatedly, Leonardo describes postmodern racism as a perceived discomfort and inability among many white people to recognize the power of race, given their "fragmented understanding of the world as it is racially structured" (2004, p.125).

These issues can be seen to impact on comparative social science research in significant ways. Foster (1999) describes "epistemological racism" in educational research today that stems from the fact that, "the social and behavioral science on which educational research has traditionally rested has been grounded in psychology, a field that has measured persons of color, women, and those from working class against a standard of White middle-class males" (pp.78-79). As critical race theorists argue, for centuries racial groups have been compared quantitatively in ways that enabled essentialist racism and white supremacy. The Scholastic Aptitude Test (SAT), widely used in the United States to measure preparedness for higher education, was modelled after intelligence tests designed "to argue for the inferiority of blacks (and relative inferiority of Southern and Eastern Europeans)" (Jackson, 2008; Roithmayr, 1998). Its author believed the test "proved the superiority of 'Nordic' races" (Jackson, 2008). Today, networking and multiplier effects make it difficult for scholars of colour to change conceptions of normal achievement or performance in order to not segregate racial minorities as others and outliers, as they remain themselves as a small minority in the research field (Foster, 1999).

A more extreme contemporary case is that of neo-scientific racism, wherein scholars continue to attribute differences in educational achievement to race, rather than institutional racism, the historical legacy of unequal education in many societies, or other factors (Kincheloe \& Steinberg, 1997, p.185). In 1994, Herrnstein and Murray published The Bell Curve, which suggested intelligence was race-based. As Kincheloe and Steinberg (1997, p.185, emphasis added) note, the book discounted important factors related to race and uneven academic achievement, including family background and socioeconomic status, home environment, and educational and other social experience:

One of the most important distortions of The Bell Curve involves the author's analysis of the Minnesota Transracial Adoption Study, in which 100 children from varying ethnic backgrounds were adopted by white parents. By the age of seven the non-white adoptees scored an average of 106 on intelligence tests...By the time the adoptees were sixteen, researchers Sandra Scarr and Richard Weinberg discovered that the non-white children's IQ scores had dropped an average of 17 points to $89 . .$. Scarr and Weinberg concluded that racial prejudice and discrimination at school had effected the 17-point decline. Other researchers agreed...when 
non-white children are raised in poor, slum-like conditions their IQ scores will be significantly lower...Despite such evidence and generally agreed upon interpretations, Herrnstein and Murray maintain [the study] revealed little environmental impact on cognitive ability.

Given this tense historical foundation and the controversial nature of identity politics today, race discourse itself has become taboo in many informal and formal (i.e., demographic) contexts. As Hollinger (2005, pp.225-226) observes,

\begin{abstract}
Almost everyone agrees that races do not exist in the sense so long assumed-biological entities carrying vastly different potentials for intelligence and social behavior, justifying the invidious treatment of inferior races-and almost everyone agrees, further, that the "racializing" of human beings, entailing their being treated differently on account of their perceived marks of descent, continues on a large scale. Yet some say that it is proper to denote as a "race" the people who have been racialized while others say not. To continue to speak of "races"...perpetuates unintentionally too many of the old racist connotations. Better to speak of "racialized persons" or to diminish the invidiousness of race by speaking of ethnoracial groups.
\end{abstract}

Ethnicity approximates the concept of race, while aiming to acknowledge "the place of history, language and culture in the construction of subjectivity and identity, as well as the fact that all discourse is placed, positioned, situated, and all knowledge is contextual" (Hall, 1989, p.226). Ethnicity is used in addition to race in places such as the United States, where a racial binary of black/ white fails to include or effectively describe and classify-for research or other purposes-different social groups, such as Asians and Latinos. Like race, ethnic categories change over time. For instance, 'Asian American' is increasingly broken down into categories such as 'East Asian,' 'Indian' and 'Pacific Islander.' Thus, ethnicity too must be seen as a fluid, context-based, social category. In the United States today, race, ethnicity and descent (as Latino or not Latino) are all currently considered in census data. 'Persons of colour' is also used to describe people not cast as white within or across societies, regardless of their racial or ethnic identity, though some feel this obscures the greater challenges black people have faced in some societies compared to ethnic minority groups (Hacker, 1992). As mentioned above, Hollinger favours "ethnoracial" (2005, p.228), but Leistnya favours "racenicity," to highlight the historical equation of "race and ethnicity within unsubstantiated claims that biological characteristics result in predisposed psychological, intellectual, and social behavior" (2001, p.425).

In other contexts, such as in Asian societies like China, ethnicity is used similarly to race, as the major or primary categorisation for internal social differences related to geographic, cultural or linguistic descent. As Shih notes, in China, "ethnicity is defined in terms of blood, religion, language, and cultural proximity to the Han. It is useful to those in the category to develop responses to their identity specification" (2002, pp.13; 24). Race and ethnicity are similarly conflated in Singapore (Bakar, 2009), and Japan (Hirasawa, 2009; Lee, 2011). 'Race' comes up more often in these settings when discussing groups regarded as outsiders to the national community; for instance 'White' and 'Chinese' may be considered as races in Hong Kong, with various ethnicities also held as important to identity among ethnic-Chinese people. In Indonesia, under Dutch colonialism, races were given as European, Malay and Chinese; within the Malay group, ethnicities were ascribed (Kuipers \& Yulaelawati, 2009, p.451). Today, Chinese Indonesians can also identify as ethnically Chinese (Kuipers \& Yulaelawati, 2009, p.456).

Clearly, race and ethnicity continue to be important factors related to equality and equity in many societies, which "sculpt the extant terrain of possibilities even when other possibilities exist" (Ladson-Billings, 1998, p.50). Educational achievement is compared by racial categories in quantitative research today which aims to document institutional racism, tracking racialisation as a factor related to educational equity. The unequal distribution of educational resources across race lines is one point of comparison. Much research compares government and/or other spending on schools predominantly attended by different racialised groups within a society, considering educational 
finance as important to achievement. For instance, Meek and Meek's (2008) study of South Africa compares per capita expenditure on education by race before and during Apartheid (p.519).

The World Inequality Database on Education (WIDE) by UNESCO offers data of educational achievement by ethnicity (among other indicators) in over 60 developing countries. It also enables studies of educational achievements by ethnicity over time, which can be used to examine progress or possible outcomes of educational interventions for increasing equality. One should use caution in conducting large-scale comparison over time, however, as racial and ethnic definitions can vary even at one site. Additionally, while synchronic analyses can capture before/after situations, it can be hard to interpret correlations as causal relationships-for instance, between an educational intervention, and an outcome-given the complexities involved with historical social science research in general.

Though race and ethnicity undoubtedly impact on educational equality and equity around the world, comparing racialised and ethnic-identity groups across countries is difficult. Contemporary definitions and categorisations of race and ethnicity vary in relation to societies' unique historical and demographic contexts. WIDE provides data on educational achievement according to ethnic groups, but these are classified as understood within countries, precluding straightforward international comparisons. Additionally, some countries do not track data on race or ethnicity and education today, including France, where neither race nor ethnicity is recognized as "a valid way of categorizing a population" (Deer, 2008, p.337). Thus, UNESCO's Education for All (EFA) Global Monitoring Report (2012a) does not systematically compare ethnicity and educational equality or equity across societies, though it identifies numerous instances where ethnicity is significant in both rich and low-income countries.

Comparisons of educational data by race and/or ethnicity across states, provinces, cities or school districts in one country are more common, and can clarify educational issues glossed over in country-level analyses. However, as Manzon writes (2007, p.105), "intranational diversity exists at the level of sub-regions and states in each country, as evidenced by statistics on demography, racial mix, and education." One should not presume that across a country racial or ethnic composition is uniform, or that local histories and political economies are equivalent. Rather, differences between locales should be examined while like groups are compared, to avoid oversimplification of findings. Recently the United States National Opportunity to Learn Campaign (2013) compared how school closures in Chicago, New York City, and Philadelphia impacted on black, Latino and white students, also comparing the percentages of students in these groups with their representation in the cities overall. Such analyses can elucidate trends and disparities across sites.

Ethnographic approaches to comparing race focus on contextual issues impacting on educational equity, through qualitative and interpretive studies. Heath's (1983) foundational study of "Roadville" and "Trackton" tracked children's school- and community-based language learning across two racially divided communities, showing how unequal access to resources (such as books) and different styles of communication at home influence teacher effectiveness and educational achievement at the individual level. Other ethnographic research in the United States has suggested that "current instructional strategies presume that African American students are deficient," often seen by white teachers as problems (Ladson-Billings, 1998, p.61). One's choice of focus can be contentious in this field, where the idea of the neutral, objective researcher is challenged, however. For instance Villegas (1988) argues that focusing on teachers' practices diverts attention from structural inequalities "that sustain the widespread academic failure of minority students," such as unequal distribution of educational resources across communities, and other factors of institutional racism discussed previously (p.253).

Additionally, the relationship of race and racism to educational achievement among other factors, such as gender and class, can be difficult to uncover. For example, in Lamontagne's study of minority education in China (1999) he observes that "the relative importance of the variables of ethnic group and territory concerning the degree of educational development" cannot be easily generalized across Chinese provinces and counties (p.149). Lamontagne found that gender disparities in China varied substantially by location and ethnicity, such that race at the individual level often 
mattered less than gender when he examined both simultaneously. Indeed, in any study on race, one must be careful to not ignore other important possible compounding or complicating factors. I now turn to considering class, as understood broadly in social science and more specifically, within contemporary comparative educational research.

\section{Class}

As with race and ethnicity, all societies have some conception of class or socioeconomic status (SES), reflective of disparate relationships of individuals to income, wealth and political-economic opportunity. And again, as with race, definitions of class and SES vary by place and time, and in relation to a society's make-up, economic dynamics, and values. Likewise, while research focusing on the relationship between education and class is increasing today in line with social justice commitments to alleviating child poverty and expanding educational equity worldwide, the socially constructed aspects of class also make it difficult to coherently use across locations, and particularly across time, as indicators continually shift.

Many historically influential theoretical frameworks have elaborated the nature of class or socioeconomic status and the relationship of individuals to resources and wealth. On one hand are those theorists in economics and sociology who favour functional, hierarchical perspectives of class, defining it as natural, necessary financial and occupational inequality resulting from progress and differentiation within a capitalist society. Durkheim (1984) is known for this view of social diversity and inequality as functional, though it also "has roots in Platonic epistemology, where intelligence is viewed as naturally and unevenly distributed" (Malott, 2009, p.285). Such views of inequality as natural or possibly good for all members of society are partly echoed by contemporary neoconservative ideologies which, for example, prioritize decreasing public expenditures on education (and other social services) over heavily taxing wealthy individuals (Malott, 2009, p.288).

Many disagree with this way of framing class, however, in sight of grave inequalities in diverse societies, which are often clearly given by birth. At the opposite extreme, Marxist theorists understand "class as a binary relation to the means of production," recognizing two classes within capitalistic (private-ownership) economic systems: those who own the means of production (bourgeoisie)-factories, equipment, knowledge and so on-and those who do not (proletariat). Within this framework the need for skilled labour for factories is highlighted as an original aim of universal education (common schools) in United States history. As Althusser (1971, p.132) argued, "the education system reproduces class by teaching "submission to the ruling ideology for the workers, and ... the ability to manipulate the ruling ideology correctly for the ... ruling class." In other words, "the education system is part of a state apparatus that cannot do otherwise than work in the interest of capital...One effect of this is that education systems of capitalist societies become inherently hierarchical and elitist" (Hill et al., 2008, p.70). Within such views ameliorating capitalism's impact on education is critical for equity.

Many contemporary sociologists of education concerned with the relationship of individuals to resources follow 'second-wave' Marxism, or 'neo-Marxism,' broadening the view of class to be constituted by interrelated cultural and material aspects. Within such theories the relationship between culture and material (economic) resources is complex and difficult to specify, as values assigned to many resources (for instance, money) are socially constructed. As Mason writes (2007, p.169), culture is "not a fixed entity [but] a dialectical process between people and their social environments," changing over time within communities. Different class-based communities can thus develop distinct orientations and values within a society. In this context Bourdieu (1968) described 'cultural capital' as empowering cultural attitudes disseminated within elite networks: "constellations...linked to the level of education, so that a typical structure of preferences in painting is most likely to be linked to a structure of preferences...in music or literature," without explicit instruction or socialization (p.210). 
Thus, as Kincheloe and Steinberg (1997) write, "economic and occupational location in a social order is one of many factors that help to construct consciousness, perception of others, and relation to power" (p.106). For example, teachers are viewed as more professional, and as part of a higher class, in some societies than in others. This impacts on their identity and outlook on life. Given the relationship of identity to class, educational sociologists examining class often focus on the way teachers treat students based on class indications, which can in turn help shape students' behaviour, achievement and sense of self (Kincheloe \& Steinberg, 1997). Some additionally argue that, at a larger scale, "even the kind of education that a student experiences is shaped by the policies and practices that favor certain ways of being and knowing... How knowledge is structured, how students learn, and what students learn reflect a process that allows some groups to organize social life to their own advantage" (Grinberg et al., 2009, p.271).

In an attempt to disaggregate cultural and ideological factors from economic ones, some favour using 'socioeconomic status' (SES) instead of class. Jacob and Holsinger distinguish class as a traditional ascribed characteristic, apart from socioeconomic status, which "can be lost, gained, or modified," through individual experiences (2008, p.14). Still, socioeconomic status remains hard to define. Occupation, education, income and wealth are four common determinants; however "they are intrinsically dependent on each other and should be analyzed together for a broader understanding of class. Moreover, these elements perhaps focus on measurable indicators that overshadow other subtle and important factors" (Grinberg et al., 2009, p.270). Additionally, such a conception of SES is also quite dynamic. For instance, "a student from a middle class background might be working his or her way through college by working at a job in the fast food industry. Does having this job make the person working class" (Grinberg et al., 2009, p.270)? One's occupation, education, income and wealth may not all fit into a single classification.

On the other hand, Savage et al. (2013) argue that frameworks which view class primarily as "features of employment relations" fail to adequately elaborate phenomena related to social mobility within particular settings, as they obscure "complex ways that class operates symbolically and culturally" (p.4). They therefore reconceive class as three-pronged within contemporary British society, consisting of 'economic capital' (income and wealth), 'cultural capital' (echoing Bourdieu), as interests and activities, and 'social capital,' as the make-up of one's social network. Using this framing they identify seven social classes in the United Kingdom, identifying distinct "new social formations...out of the tendrils of the traditional working class," which has typically been seen as rather homogenous, stable and relatively immobile (Savage et al., 2013, p.28).

While useful for understanding how class operates in the particular context of the United Kingdom today, it would be difficult to export this model to make international comparisons, however. As Ali and Dadush (2012) argue, for purposes of international comparison most categorisations of class are unhelpful, owing to variations in socioeconomic and cultural contexts across the world, as well as methodological challenges in gaining accurate data. They propose car ownership as a possible measure of membership in the middle-class or higher class levels, as "an unambiguous indication of the ability to purchase other luxury goods." However, one only need think of Hong Kong, where car taxes can be up to $100 \%$ of a car's value-or wide variability in quality and access of public transportation across societies - to recognize this is also a subjective, value-laden measure of political-economic status across societies.

In quantitative educational research, class or SES is often conceived in terms of "family background," which focuses on the education, wealth, income, occupation of parents and/or other aspects related to family structure (number of the children in the family, among others). Due to complications labelling people according to these possibly divergent indicators, educational researchers may favour studying one or more of these variables independently-for instance, comparing educational achievement with family income, father's educational background and mother's educational background, as in one recent study of Taiwanese educational inequality (Hung $\&$ Cheng, 2008). Alternatively class can be understood in terms of access to a computer at home, 
or eligibility for free school lunch or reduced tuition (Grinberg et al. 2009), though such factors are of course context-specific.

Two quantitative tools developed specifically for studying class in educational research include the PISA index of economic, social and cultural status (ESCS), and the education Gini coefficient. The ESCS is a measure of individual status (OECD, 2009) based upon the highest occupational status of parents from an international socioeconomic index, the highest educational level of parents and highest educational level of parents and index of home possessions (e.g. a quiet place to study, a link to the Internet, their own calculator, among others).

Such data can be difficult to gather, however, as it requires interviewing or surveyingadditionally, how to weight items for international comparison would remain challenging.

The education Gini coefficient is based on the original Gini coefficient, a commonly-used measure of income distribution and inequality within a country, developed in the early-twentieth century by sociologist Corrado Gini (Burt \& Park, 2008). The education Gini is an equation based on distribution of educational attainment and average years of schooling for a population, proportion of the population with given levels of schooling and the number of years of schooling at each of the different educational levels (Burt \& Park, 2008). As with the original Gini coefficient, the education Gini can be used to compare populations across places and time periods, but does not "specify the location of inequality within the distribution of the measured variable" (Burt \& Park, 2008, p.264). Interestingly, while many Marxist-influenced sociologists of education argue that capitalism creates or exacerbates educational inequality (e.g., Hill et al., 2008; Malott, 2009), the education Gini has been positively correlated with capital/income across countries in recent decades (Jacob \& Holsinger, 2008, pp.10-12).

In comparative educational research, multiple methods of analysis can be used to explain class, depending upon context, units of comparison and research questions. Many studies compare educational equity by class or socioeconomic status within a national, regional, or local context. Depending upon the focus for comparison, a qualitative, quantitative or hybrid methodology may be preferred. Quantitative approaches can compare educational achievements (i.e. years of education or graduation rates) of students of different socioeconomic statuses (or ESCS). UNESCO/WIDE data enables comparison of educational achievements from the poorest 20 percent to the wealthiest 20 percent and groups in-between within developing countries, while the OECD compares educational achievements within countries with father's educational level (2007). Such approaches can yield relational data between factors related to class and educational equality, and commonly reflect a strong relationship between the two.

It can be difficult to decide which measures to use in such quantitative research, however, as common factors may be proxies for more particular, explanatory data. Thus multilevel or meta-analyses complementing quantitative data with qualitative findings can be included to help substantiate claims. In Mclnerney's (2010) study of Hong Kong, socioeconomic status, family background and family income are correlated with educational achievement; he uses related research to illustrate (p.9) how these are causally related:

Family income matters in terms of providing access to more expensive, higher-quality secondary schools and to extra tutorial support, enhancing the opportunity of students(...) Among the potential liabilities of coming from low SES background are more limited choice of schools, limited opportunity for tuition owing to costs, poorer provision of educational resources, less supervision of study time because parents work long hours, financial stress that might provide a non-conducive learning environment at home.

Likewise, Manzon (2007, p.105) describes a multilevel analysis juxtaposing national cultural differences with ethnographic student reports across England and France to relate "findings at the lower level of the student and classroom to the higher level of cross-cultural differences and teaching 
traditions," combining qualitative and quantitative approaches in studying class and educational inequality. A blend of philosophical-analytic, ethnographic and statistical analysis helps present a more holistic picture of such complex, contextual phenomenon.

Data such as WIDE can also demonstrate how class factors relate to educational equity within communities or societies over time. However, it can be difficult to identify how changes in the economy and/or in the value of currency or other educational resources interact with class factors in time-based comparison. For instance, the gap in educational achievements between the poorest and wealthiest 20 percent within a society may decrease-yet this would not necessarily indicate that educational achievements are increasing on the whole. Research in Britain recently showed that "poorer students are more likely to go into higher education than they were in the past," though "the likelihood of them doing so relative to their richer peers is actually lower" (Hill et al., 2008, p.77). The policy implications of considering only one of these findings apart from the other could be quite different. Similarly Hill et al. (2008) take issue with the World Bank's report that private education can benefit the lowest socioeconomic groups by "siphoning off 'educational investments' from wealthier pupils," without attending to other factors of inequality such as students' disparate cultural and social capital (p.78). The politics of understanding and defining class relations in research remains contentious today, though the topic is not so taboo as race and ethnicity.

Additionally, definitions of terms, such as 'poverty,' and relevant classifications of attainment are fluid over time. Burt and Park's (2008) comparison of the education Gini over four decades in Korea used different categories for educational achievement based on the data available, which reflected different norms in achievement during the timeframe. For instance, in the 1970s and 1980s, categories were "graduated," "not completed" and "never attended," whereas in the 1990s "general high school" and "vocation high school" were split; in 2000, "graduated" was split from "completed," while "graduated master's course," "graduated doctor's course," "dropped out of master's course" and "dropped out of doctor's course," were added (pp.264-265). Deciding how to deal with such shifts is not often straight-forward.

Many studies compare education Gini coefficients, or the correlation between class indicators such as ESCS, family background, wealth, among others, to educational achievements, across intranational regions or countries. The education Gini has been used to compare inequity across different regions within a country, such as Korea (Burt \& Park, 2008), or internationally (Jacob \& Holsinger, 2009; Thomas \& Wang, 2008). Additionally, it can be correlated to indicators of national wealth such as Gross Domestic Product (GDP) (Jacob \& Holsinger, 2008). WIDE/UNESCO data enables comparison across percentiles of wealth across countries, though with such data sets it may be difficult to ensure the information is accurate, or collected from the same time period: for instance, a 2010 UNESCO report compares educational achievement to wealth across several countries, using data from 2000 for Gabon and from 2007 in the Democratic Republic of Congo (p.140). Such representations better portray broad themes across a wide variety of countries than they reveal the results of inputs, or enable direct comparisons.

Qualitative researchers examine social reproduction of inequality through teacher-student interaction in schools, as mentioned previously. For instance, researchers might compare pedagogical strategies used in one school across classrooms made up of poor students and middle-class students; indeed, research conducted along these lines has identified that teachers often regard economically disadvantaged students in "cold, impersonal ways" (Kincheloe \& Steinberg, 1997, p.128). Oakes' (1985) foundational work on tracking (streaming) in education found that often students are socialized differently through their educational experiences in ways echoing Marxist theorists' concerns with education as class reproduction. Curricula can also be examined for overt or subtle messages in textbooks or lessons which suggest particular orientations to social inequality. Of course, race and gender (among other factors) can also quickly become apparent in such analyses, disabling reflexive researchers from attaining a universalistic understanding of class or SES when analysing dynamic educational contexts where student identities are informed by class, race, and more. 


\section{Discussion}

As discussed here, structural inequalities shape educational opportunities by race and ethnicity across diverse societies, in relation to factors such as educator or societal prejudice, multiplier and networking effects, the 'invisible knapsack' and so on. Class also impacts on educational equity, as youth have differential advantages and disadvantages related to family background, culture, and income, all of which have a clear facilitative role in enabling student educational achievement across societies. Nonetheless, as this exploration shows, what race/ethnicity and class mean in the development and design of instruments and tools that isolate factors for research to ameliorate educational injustice cannot be prescribed in comparative studies, but must always be analysed within distinct social contexts. This requirement makes comparative educational work especially difficult, given the fluidity and different understandings of these terms and their significance, even in one site over time, or across seemingly like locations.

I have focused on race and class separately here, to expose challenges for focusing on either category in relation to educational inequality. However, arguably no research should be conducted without additional attention to how race and class impact on one another-as well as other critical factors, particularly gender. In contrast with race and class, gender is a straightforward category to use. As Airton notes (2009, pp.223-224) few studies "even define the terms sex, gender, boy, girl, male female, etc." Some may feel gender is less important than race or class, particularly when working in the context of modern Western societies: Globally, women have reached parity with men in earning bachelor's degrees, and "have an edge over men of 56 to 44 percent in master's degrees" (UNESCO, 2012 b, p.80). However, research across diverse societies, including those known for gender equality, nonetheless continues to demonstrate that gender impacts educational expectations, socialising boys and girls differently in schools (Gordon et al., 2000) and influencing trends in educational attainment (Hyer et al., 2008). In most societies women remain underrepresented in fields with clear vocational tracks (such as university-facilitated paid apprenticeships), in mathematics and science, and at the PhD level (UNESCO, 2012b) - as well as in employment worldwide. Gender also remains a vital factor barring girls' access to education across many developing countries (Unterhalter \& Oommen, 2008), in relation to race, ethnicity, and class.

As the inquiry here into the meaning, definition, and significance of race and class reveals, the importance of race and class (and gender) are highly dependent on social context, as are the impacts of each on one another as complex compounding forces. Race, class, and gender disadvantages (and advantages) build onto one another in ways that change individuals' experiences qualitatively, not merely adding more hurdles (all of similar height), but rather impacting on hurdles' heights and locations, changing the playing field for individuals based on their particular identity construction, which may also vary as one moves from the suburbs to the city (or vice versa), from primary to secondary school, and so on. Thus, without considering the particular ways race and class (and gender) interact in specific contexts, is it difficult to understand and ameliorate real-life educational inequality.

For example, 'affirmative action' enabling more equal higher education admission of prepared candidates by race as a means to ameliorate African American disadvantage in the United States is held by many as a failure, as most people who gain from such programmess are among the wealthiest groups in the society (Jackson, 2008). Though some socioeconomically disadvantaged African Americans have gained greater access to university entrance through such programmes, substantial numbers within this group fail to attain their degrees, due to disadvantages in preparedness and/or means to continued success, which come with class inequality, rather than racial inequality. Without attention to the relation between race and class in individual's lives and in specific communities, such policies and programmes are unlikely to succeed, owing to simplistic understanding of these factors' roles in educational inequality. The use of large-scale quantitative approaches may be particularly ill-advised for understanding such important cases and responding to them effectively, as parsing out the factors of race and class in studying large-scale populations remains challenging. 
Finally, one must be diligent in examining such politically contentious and conceptually fluid factors that they do not allow assumptions about the way the factors operate and interact to bias their analyses. As Fairbrother cautions, given comparative education's aim to "seek global solutions to global problems...effort must be made to become conscious of biases and to question one's own assumptions while trying to understand the assumptions underlying the societies and cultures which are the targets of the research" (2007, p.48). Querying assumptions about race and class gained even from one's academic or professional context can be important to ensure one does not make assumptions about issues and contexts that require critical investigation, not borrowing principles and theories of race and class from one time or place to another simplistically. In other words, as race and class are conceived in different ways across contemporary contexts, their force and the nature of their interrelationships should not be presumed in comparative education, given the complex ways these factors are understood to continue to impact on educational attainment today.

\section{Conclusion}

Though race and class are two of the most significant social categories seen to underpin and organize educational inequality and inequity across world regions, their complex interplay, dynamic meanings and structural nature make them difficult to use in comparative education. They are challenging to categorize and thus to use effectively across different social contexts. Furthermore, as structural factors, race and class (and gender) can be seen to impact on each other in particular ways that do not lend themselves to generalizability, creating new hurdles for comparative educational research seeking answers to large-scale or global questions related to educational equality. Additional compounding features, such as language, religion, ability and so on, can also have a significant role in shaping educational opportunity and achievement, and one or more of these may also be found as crucial components in educational inequality depending on the social context of research.

As Mason writes, "educational research yields the most worthwhile results, at least with respect to [the goals of] equality and equity, when researchers attempt, from the very conceptualization of their projects, to identify the axes along which educational and other goods are differentially distributed, and to disaggregate their object of study along those axes" (2007, p.196). Comparative educational research on race and class (and other personal identity characteristics, such as gender, ability, religion, language and so on) has a challenging task, to compare categories within and across often-diverse schools and societies, without framing categories used as homogenous social groups, attending to complex interrelation and the compounding impacts of these categories in shaping educational opportunity and achievement. Conceiving comparative education as Mason does, "as a critical social science, incorporating an emancipatory interest focused on the distribution of power and its associated attributes" (2007, p.196), comparative researchers should continually query the meaning and significance of race and class as distinct but qualitatively compounding impacts on individual access and achievement, comparing contexts as well as social groups, to illustrate rather than obscure the difference these factors can make in shaping people's lives.

\section{References}

Airton, L. (2009). Untangling 'gender diversity': Genderism and its discontents (i.e., everyone). In Steinberg, S. R. (Ed.), Diversity and Multiculturalism: A Reader. New York: Peter Lang, pp.223246.

Ali, S. S. \& Dadush, U. (2012). The global middle class is bigger than we thought: A new way of measuring prosperity has enormous implications for geopolitics and economics. Foreign Policy, 24 May.

Althusser, L. (1971). Lenin and Philosophy, and Other Essays, trans. London: New Left Books. 
Bakar, M. A. (2009). Islamic religious education and Muslim religiosity in Singapore. In J. Banks (Ed.), The Routledge International Companion to Multicultural Education. New York: Routledge, pp.437-448.

Bourdieu, P. (1968). Outline of a theory of art perception. International Social Science Journal, 2(4), 589-612.

Burt, M. E. \& Park, N. (2008). Education inequality in the Republic of Korea: Measurement and causes. In D.B. Holsinger \& W. Jacob (Eds.), Inequality in Education: Comparative and International Perspectives. Hong Kong: Comparative Education Research Centre, The University of Hong Kong, and Dordrecht: Springer, pp.261-289.

Deer, C. (2008). Different paths, similar effects: Persistent inequalities and their sources in European higher education. In D. B. Holsinger \& W. Jacob (Eds.), Inequality in Education: Comparative and International Perspectives. Hong Kong: Comparative Education Research Centre, The University of Hong Kong, and Dordrecht: Springer, pp.324-347.

Durkheim, E. (1893/1984). The Division of Labor in Society. New York: Free Press.

Fairbrother, G. P. (2007). Quantitative and qualitative approaches to comparative education. In M. Bray, B. Adamson, \& M. Mason (Eds.), Comparative Education Research: Approaches and Methods. Hong Kong: Comparative Education Research Centre, The University of Hong Kong, and Dordrecht: Springer, pp.39-62.

Foster, M. (1999). Race, class, and gender in education research: Surveying the political terrain. Educational Policy, 13(1), pp.77-85.

Goldie, T. (1989). The representation of the Indigene. In Ashcroft, B., Griffiths, G. \& Tiffin, H. (Eds.), The Post-Colonial Reader. New York: Routledge, pp.232-236.

Gordon, T., Holland, J. \& Lahelma, E. (2000). From pupil to citizen: A gendered route. In Arnot, M. \& Dillabough, J. (Eds.), Challenging Democracy: International Perspectives on Gender, Education and Citizenship. London: RoutledgeFalmer, pp.187-202.

Grinberg, J., Price, J. \& Naiditch, F. (2009). Schooling and social class. In S. Steinberg (Ed.), Diversity and Multiculturalism: A Reader. New York: Peter Lang, pp.265-278.

Hacker, A. (1992). Two Nations: Black and White, Separate, Hostile, Unequal. New York: Scribner.

Hall, S. (1989/1995). New ethnicities. In B. Ashcroft, G. Griffiths \& H. Tiffin (Eds.), The Post-Colonial Studies Reader. New York: Routledge, pp.223-227.

Heath, S. B. (1983). Ways with Words: Language, Life, and Work in Communities and Classrooms. Cambridge: Cambridge University Press.

Herrnstein, R. J. \& Murray, C. (1994). The Bell Curve: Intelligence and Class Structure in American Life. New York: Free Press.

Hill, D., Greaves, N. M. \& Maisuria, A. (2008). Does capitalism inevitably increase inequality? In D. B. Holsinger \& W. Jacob (Eds.), Inequality in Education: Comparative and International Perspectives. Hong Kong: Comparative Education Research Centre, The University of Hong Kong, and Dordrecht: Springer, pp.59-85.

Hirasawa, Y. (2009). Multicultural education in Japan. In J. Banks (Ed.), The Routledge International Companion to Multicultural Education. New York: Routledge, pp.159-170.

Hollinger, D. A. (2005). Postethnic America: Beyond Multiculturalism. New York: Perseus.

hooks, b. (1994). Teaching to Transgress: Education as the Practice of Freedom. New York: Routledge.

Hung, C. C. \& Cheng, S. Y. (2008). Access and equity: Who are the students at Taiwan's top universities? In D.B. Holsinger \& W. Jacob (Eds.), Inequality in Education: Comparative and International Perspectives. Hong Kong: Comparative Education Research Centre, The University of Hong Kong, and Dordrecht: Springer, pp.290-306.

Hyer, K. E., Ballif-Spanvill, B., Peters, S. J., Solomon, Y., Thomas, H. \& Ward, C. (2008). Gender inequalities in educational participation. In D.B. Holsinger \& W. Jacob (Eds.), Inequality in Education: Comparative and International Perspectives. Hong Kong: Comparative Education Research Centre, The University of Hong Kong, and Dordrecht: Springer, pp.128-148.

Jackson, L. (2008). Reconsidering affirmative action in education as a good for the disadvantaged. Journal for Critical Educational Policy Studies, 6(1), 1-15. 
Jacob, W. J. \& Holsinger, D. B. (2008). Inequality in education: A critical analysis. In D.B. Holsinger, \& W. Jacob (Eds.), Inequality in Education: Comparative and International Perspectives. Hong Kong: Comparative Education Research Centre, The University of Hong Kong, and Dordrecht: Springer, pp.1-33.

Keevak, M. (2011). Becoming Yellow: A Short History of Racial Thinking. Princeton: Princeton University Press.

Kincheloe, J. L. \& Steinberg, S. R. (1997). Changing Multiculturalism. Buckingham: Open University Press.

Kuipers, J. C. \& Yulaelawati, E. (2009). Religion, ethnicity, and identity in Indonesian education. In J. Banks (Ed.), The Routledge International Companion to Multicultural Education. New York: Routledge, pp.449-460.

Ladson-Billings, G. (1998). Just what is Critical Race Theory and what's it doing in a nice field like education? International Journal of Qualitative Studies in Education, 11(1), 7-24.

Lamontagne, J. (1999). National minority education in China: A nationwide survey across counties. In G. Postiglione (Ed.), China's National Minority Education: Culture, Schooling, and Development. New York: Falmer.

Lee, S. Y. (2011). Changing faces: Colonial rule in Korea and ethnic characterizations. In Y. Takezawa (Ed.), Racial Representations in Asia. Kyoto: Kyoto University Press, pp.53-74.

Leonardo, Z. (2004). The souls of white folk: Critical pedagogy, Whiteness Studies, and globalization discourse. In D. Gillborn \& G. Ladson-Billings (Eds.), The RoutledgeFalmer Reader in Multicultural Education. London: RoutledgeFalmer, pp.117-136.

Leistyna, P. (2001). Racenicity: Understanding racialized ethnic identities. In S. Steinberg (Ed.), Multi/ Intercultural Conversations: A Reader. New York : Peter Lang, pp.423-462.

Malott, C. S. (2009). An introduction to social class and the division of labor. In S. Steinberg (Ed.), Diversity and Multiculturalism: A Reader. New York: Peter Lang, pp.279-296.

Manzon, M. (2007). Comparing places. In M. Bray, B. Adamson \& M. Mason (Eds.), Comparative Education Research: Approaches and Methods. Hong Kong: Comparative Education Research Centre, The University of Hong Kong, and Dordrecht: Springer, pp.85-122.

Mason, M. (2007). Comparing cultures. In M. Bray, B. Adamson, \& M. Mason (Eds.), Comparative Education Research: Approaches and Methods. Hong Kong: Comparative Education Research Centre, The University of Hong Kong, and Dordrecht: Springer, pp.165-196.

McCarthy, C. (2003). After the canon: Knowledge and ideological representation in the multicultural discourse on curriculum reform. In C. McCarthy \& W. Crichlow (Eds.), Race, Identity, and Representation in Education. New York: Routledge.

McInerney, D. M. (2010). The Role of Sociocultural Factors in Shaping Student Engagement in Hong Kong: An Ethnic Minority Perspective. Hong Kong: Hong Kong Institute of Education.

McIntosh, P. (1990). White privilege: Unpacking the invisible knapsack. Independent School, Winter, 31-36.

Meek, C. B. \& Meek, J. Y. (2008). The history and devolution of education in South Africa. In D.B. Holsinger \& W. Jacob (Eds.), Inequality in Education: Comparative and International Perspectives. Hong Kong: Comparative Education Research Centre, The University of Hong Kong, and Dordrecht: Springer, pp.506-537.

Oakes, J. (1985). Keeping Track: How Schools Structure Inequality. New Haven: Yale University Press.

OECD (2007). Education at a Glance 2007. Paris: Organisation for Economic Co-operation and Development (OECD).

OECD (2009). Equally Prepared for Life? How 15-Year-Old Boys and Girls Perform in School. Paris: Organisation for Economic Co-operation and Development (OECD).

Omi, M. \& Winant, H. (1993). On the theoretical status of the concept of race. In C. McCarthy \& W. Crichlow (Eds.), Race, Identity, and Representation in Education. New York: Routledge, pp.3-10.

Padilla, L. M. (1997). Intersectionality and positionality: Situating women of color in the affirmative action dialogue. Fordham Law Review, December, .843,853-885.

Ravitch, D. (1990). Multiculturalism: E Pluribus Plures. The American Scholar, 59(3), 337-354. 
Roithmayr, D. (1998). Deconstructing the distinction between bias and merit. La Raza Law Journal, $10,363-421$.

Savage, M., Devine, F., Cunningham, N., Taylor, M., Li, Y., Hjellbrekke, J., Le Roux, B., Friedman, S., \& Miles, A. (2013). A new model of social class: Findings from the BBC's Great British Class Survey Experiment. Sociology, 47(2), 219-250.

Shih, C. (2002). Negotiating Ethnicity in China: Citizenship as a Response to the State. New York: Routledge.

Sollors, W. (1986). Who is ethnic? In B. Ashcroft, G. Griffiths \& H. Tiffin (Eds.), The Post-Colonial Reader. New York: Routledge, pp.219-222.

Takezawa, Y. (2011). Racial Representations in Asia. Kyoto: Kyoto University Press.

Thomas, V. \& Wang, Y. (2008). Distribution of opportunities key to development. In D.B. Holsinger, \& W. J. Jacob (Eds.), Inequality in Education: Comparative and International Perspectives. Hong Kong: Comparative Education Research Centre, The University of Hong Kong, and Dordrecht: Springer, pp.34-58.

Unterhalter, E. \& Oommen, M. (2008). Measuring education inequalities in commonwealth countries in Africa. In D.B. Holsinger \& W. Jacob (Eds.), Inequality in Education: Comparative and International Perspectives. Hong Kong: Comparative Education Research Centre, The University of Hong Kong, and Dordrecht: Springer, pp.506-537.

UNESCO (2010). Reaching the Marginalized: Education for All Global Monitoring Report 2010. Paris: UNESCO.

UNESCO (2012a). Youth and Skills - Putting Education to Work: Education for All Global Monitoring Report 2012. Paris: UNESCO.

UNESCO (2012b). World Atlas of Gender Equality in Education. Paris: UNESCO.

UNESCO (2013). World Inequality Database on Education. Available at: http://www.educationinequalities.org [Accessed 28 May 2014]

United States National Opportunity to Learn Campaign (2013). The Color of School Closures. Available at: http://www.otlcampaign.org/blog/2013/04/05/color-school-closures [Accessed 28 May 2014]

Villegas, A. M. (1988). School failure and cultural mismatch: Another view. Urban Review, 20, 253-265. 